\title{
Study of Adsorption Isotherms and Kinetic Models of Methylene Blue Adsorption on Moroccan Bagasse Waste
}

\author{
Fatiha Moughaoui, Amine Ouaket, Malak Eddebbagh, Ahmed Bennamara, \\ Abdelmjid Abourriche, Zoubida Anbaoui and Mohammed Berrada \\ Biomolecules and Organic Synthesis Laboratory, Faculty of Science Ben M'sik, \\ University Hassan II-Casablanca. Morocco
}

\begin{abstract}
In this study, bagasse was used as a natural available raw biomass adsorbent for the removal of methylene blue $(M B)$ from aqueous solutions. The equilibrium isotherms data were analyzed by the Langmuir, Freundlich and Temkin models of adsorption and the kinetic data obtained at different concentrations were investigated using pseudo-first-order and pseudo-second-order kinetic models and for determining the applicability of various models. The kinetic approaches were based on the better correlation coefficient $\left(R^{2}\right)$ and the normalized standard deviation $(\Delta q(\%))$ to find out the best-fit isotherm and kinetic equation. The different parameters of the best-fit model were calculated and discussed.

Equilibrium data fitted well with the Langmuir model with maximum monolayer adsorption capacity of 41,67 $\mathrm{mg} / \mathrm{g}$ at $25^{\circ} \mathrm{C}$, the dimensionless factor, $R_{L}$ revealed the favorable nature of the isotherm. The adsorption kinetics data showed that this process can be described by the pseudo-second-order model with good correlation from which the rate constant and the adsorption capacity were determined.
\end{abstract}

Keywords: Adsorption, Moroccan Bagasse, MB adsorption, Isotherm, Kinetic models, Error analyses.

\section{Introduction}

The industrial effluents cause serious problems as they are the major source for contamination of water, especially dyes production industries like textile, paper, cosmetic, rubber, plastic etc. Among these different industries, textile industry constitutes enormous effects to the human health and to the environment because it ranks first in usage of dyes. Since dyes have a synthetic origin and complex aromatic molecular structures, are inert and difficult to biodegrade when discharged into waste streams[1]. Hence, removal of dyes from such wastewaters is a major environmental problem and complete dye removal is necessary because dyes will be visible even at low concentration[2]-[4]

Recently a number of research attracted attention for the removal of this pollutants from wastewater systems and the most widely used methods for removing it include physicochemical, chemical, and biological methods, such as precipitation, coagulation/flocculation, ion exchange, reverse osmosis, complexation/sequestration and electrochemical operations[5], [6]. Adsorption techniques employing solid sorbents are widely used to remove certain classes of synthetic pollutants from waters, especially those that are not easily biodegradable because of the negligible one-time investment, easy separation, effective and useful process [5], [7], [8].

Recently attention has been diverted towards the biomaterials which are byproducts or the wastes from large scale industrial operations and agricultural waste materials. This is due to their advantages of biosorption over conventional treatment methods like: low cost, high efficiency, minimization of chemical or biological sludge, no additional nutrient requirement, and regeneration of biosorbents, sustainability, recyclability, cost effectiveness, environmentally friendliness[9]. Bagasse is a waste obtained from the fired boiler stack of cane sugar mills after crushing to extract their juice. It is currently being used to produce energy for sugar mills and as 
filer in building materials but it is still insignificant on term of valorization so a suitable utilization of this residue is an important target to be pursue.

The main objective of this study was undertaken to evaluate the feasibility of removing the Methylene Blue (MB) dye from aqueous solution by adsorption onto Moroccan sugarcane bagasse. The equilibrium and kinetic data of the adsorption were then studied to understand the adsorption process.

\section{Materials and Methods}

\subsection{Preparation of the Adsorbent}

Sugarcane bagasse was obtained from a local sugar factory (Morocco). It was first dried in sunlight and then the fibers cut into small pieces. The cut bagasse was ground and sieved to pass a $150 \mu \mathrm{m}$ size screen. The material was then washed with distilled water under stirring at $70{ }^{\circ} \mathrm{C}$ for $2 \mathrm{~h}$ and dried overnight in an oven at $50{ }^{\circ} \mathrm{C}$.

\subsection{Adsorbate: Methylen Blue}

Methylene blue (MB), a typical cationic dye, is often founded in dye wastewater. Owing to its non biodegradation and stability, MB can exist stably in the dye wastewater, its known strong adsorption onto solids, and it recognized usefulness in characterizing adsorptive material[8], [10], [11]. It was chosen in this study as a model compound to study the adsorption performance of dye on bagasse.

The stock solution was prepared by dissolving a crystallized product of dye in distilled water to the concentration of $100 \mathrm{mg} / \mathrm{L}$. The experimental solutions of the desired concentrations were obtained by successively dilutions of the dye stock solution.

\subsection{Analytical Measurements}

Concentrations of dyes in the solution were measured colourimetrically using an UV spectrophotometer (type UV-3100PC). A standard solution of the dye was taken and the absorbance was determined at different wavelengths to obtain a plot of absorbance versus wavelength. The wavelength corresponding to maximum absorbance $\left(\lambda_{\max }\right)$ was determined from this plot and it was found to be $664 \mathrm{~nm}$.

\subsection{Adsorption isotherm Experiments}

Experiments with dye MB and bagasse was performed to determine the adsorption isotherms. Equal masses of $0,1 \mathrm{~g}$ of bagasse of particle size $(>150 \mu \mathrm{m})$ were added to $250 \mathrm{~mL}$ Erlenmeyer flasks containing $100 \mathrm{~mL}$ of dye solutions of initial concentration, varying over a range of $10-30 \mathrm{mg} / \mathrm{L}$ at $25{ }^{\circ} \mathrm{C}$ for $1 \mathrm{~h}$. Agitation was made under constant stirring using magnetic stirrer. Each experiment was performed using the greatest adsorption obtained from kinetic studies [12].

The amount of dye adsorbed at equilibrium, $\mathrm{q}_{\mathrm{e}}(\mathrm{mg} / \mathrm{g})$ was calculated using the following equation (1):

$$
\mathbf{q}_{\mathbf{e}}=\frac{\left(\mathbf{C}_{\mathbf{i}}-\mathbf{C}_{\mathrm{e}}\right) * \mathrm{~V}}{\mathrm{~W}}
$$

Where $C_{i}$ and $C_{e}(m g / L)$ are the concentrations of $B M$ at initial and equilibrium, respectively. $V$ is the volume of the solution ( $\mathrm{L})$ and $\mathrm{W}$ is the weight of the adsorbent used $(\mathrm{g})$.

- Error analysis

To compare more definitely the validity of each isotherm models, a normalized standard deviation, $\Delta \mathrm{q}_{\mathrm{e}}(\%)$ is calculated as given by the equation (2)[13]:

$$
\Delta \mathrm{q}_{\mathrm{e}}(\%)=\frac{\sqrt{\left[\frac{\mathrm{q}_{\mathrm{e}, \mathrm{exp}}-\mathrm{q}_{\mathrm{e}, \mathrm{cal}}}{\mathrm{q}_{\mathrm{e}, \mathrm{exp}}}\right]^{2}}}{\mathrm{~N}-1} \times 100
$$

Where $\mathrm{q}_{\mathrm{e}, \mathrm{exp}}(\mathrm{mg} / \mathrm{g})$ and $\mathrm{q}_{\mathrm{e}, \mathrm{cal}}(\mathrm{mg} / \mathrm{g})$ are the experimental and calculated values for the amount of MB adsorbed, respectively and $\mathrm{N}$ is the number of measurements. 


\subsection{Adsorption Kinetic Experiments}

In the kinetic study, the adsorption experiments were carried out by agitating the selected amount of adsorbent in $100 \mathrm{~mL}$ aqueous solution of $\mathrm{MB}$ at a concentration of $20 \mathrm{mg} / \mathrm{L}$. MB content in the solutions were analysed at regular intervals. The pseudo-first-order, the pseudo-second-order were used to evaluate the adsorption kinetics. The amount of adsorption at time $\mathrm{t}, \mathrm{q}_{\mathrm{t}}(\mathrm{mg} / \mathrm{g})$, was calculated by equation (3):

$$
\mathrm{q}_{\mathrm{t}}=\frac{\left(\mathrm{C}_{\mathrm{i}}-\mathrm{C}_{\mathrm{t}}\right) * \mathrm{~V}}{\mathrm{~W}}
$$

Where $C_{i}$ and $C_{t}(m g / L)$ are the concentrations of $M B$ at initial and at any time $t$, respectively. $V$ is the volume of the solution (L) and $\mathrm{W}$ is the weight of the adsorbent used $(\mathrm{g})$.

In order to compare the applicability of different kinetic models, a normalized standard deviation, $\Delta \mathrm{q}_{\mathrm{t}}(\%)$ is given as follows equation (4)[14], [13]:

$$
\Delta \mathrm{q}_{\mathrm{t}}(\%)=\frac{\sqrt{\sum\left[\frac{\mathrm{q}_{\mathrm{t}, \exp }-\mathrm{q}_{\mathrm{t}, \mathrm{cal}}}{\mathrm{q}_{\mathrm{t}, \mathrm{exp}}}\right]^{2}}}{\mathrm{~N}-1} \times 100
$$

Where $\mathrm{q}_{\mathrm{t}, \text { exp }}(\mathrm{mg} / \mathrm{g})$ and $\mathrm{q}_{\mathrm{t}, \mathrm{cal}}(\mathrm{mg} / \mathrm{g})$ are the experimental and calculated value for the amount of MB adsorption at time $\mathrm{t}$, respectively and $\mathrm{N}$ is the number of measurements.

\section{Results and Discussions}

\subsection{Adsorption Isotherm}

The adsorption isotherms are helpful to explicate the adsorbate-adsorbent interaction and to determine the capacity of adsorbent when the adsorption process reaches an equilibrium state. The parameters of the isotherm models offer significant information on the adsorption mechanisms and the surface properties and efficiencies of the adsorbent [13].

The equilibrium isotherm determined at $298 \mathrm{~K}$ is presented in (Fig. 1). It can be observed that the adsorption capacity increased with increase in equilibrium concentration and finally attained a saturated value for MB, the adsorption isotherm belong to L type according to the classification of Giles [14].

However, several models have been used to describe the experimental data and three important isotherms were applied in this study: the Langmuir, Freundlich and Temkin isotherms.

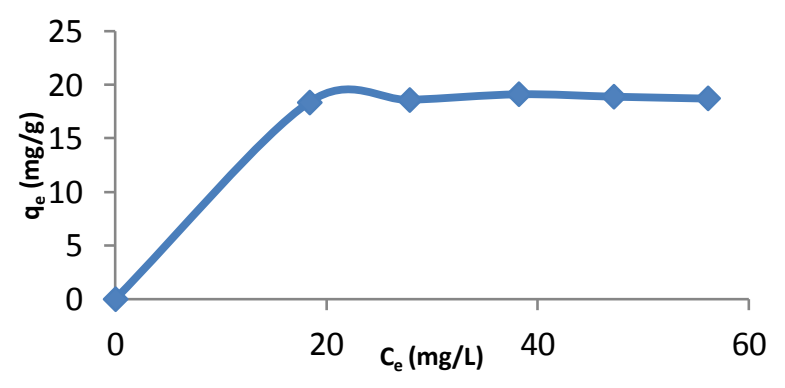

Fig. 1: Equilibrium isotherms of MB onto bagasse at different concentrations

Langmuir Isotherm: the Langmuir isotherm model assumes monolayer adsorption takes place on homogeneous surfaces and there is no interaction between the adsorbed molecules. The linearized form of Langmuir equation can be written as follows equation (5):

$$
\frac{\mathrm{C}_{\mathrm{e}}}{\mathrm{q}_{\mathrm{e}}}=\frac{1}{\mathrm{q}_{\mathrm{m}} \mathrm{b}}+\frac{\mathrm{C}_{\mathrm{e}}}{\mathrm{q}_{\mathrm{m}}}
$$

Where $\mathrm{q}_{\mathrm{m}}$ is the greatest equilibrium adsorption capacity $(\mathrm{mg} / \mathrm{g})$ and $\mathrm{b}$ is the adsorption equilibrium constant $(\mathrm{L} / \mathrm{mg})$. The values of $\mathrm{q}_{\mathrm{m}}$ and $\mathrm{b}$ can be calculated from the plot of $\mathrm{C}_{\mathrm{e}} / \mathrm{q}_{\mathrm{e}}$ versus $\mathrm{C}_{\mathrm{e}}$ (Fig. 2) 
Freundlich isotherm: is an empirical equation which assumes that the adsorption takes place on heterogeneous surface and is expressed by the following equation (6):

$$
\ln \mathrm{q}_{\mathrm{e}}=\ln \mathrm{K}_{\mathrm{F}}+\frac{1}{\mathrm{n}} \ln \mathrm{C}_{\mathrm{e}}
$$

Where $\mathrm{q}_{\mathrm{e}}(\mathrm{mg} / \mathrm{g})$ is the adsorption capacity at equilibrium, $\mathrm{C}_{\mathrm{e}}(\mathrm{mg} / \mathrm{L})$ is the equilibrium concentration of the $\mathrm{MB}, \mathrm{K}_{\mathrm{F}}(\mathrm{mg} / \mathrm{g})(\mathrm{L} / \mathrm{mg})^{1 / \mathrm{n}}$ and $\mathrm{n}$ are Freundlich constants characteristic of the system related to adsorption capacity and adsorption intensity. The $\mathrm{n}$ value indicates the degree of non-linearity between solution concentration and adsorption as follows: if $n=1$, the adsorption is linear; if $n<1$, the adsorption process is chemical and if $n>1$, the adsorption is a favorable physical process[10]. The values of $K_{F}$ and $1 / n$ can be calculated from the slopes and the intercepts of the plot of $\operatorname{lnq}_{\mathrm{e}}$ versus $\operatorname{lnC}_{\mathrm{e}}$.

Temkin isotherm: assumes that heat of adsorption of all the molecules in the layer decreases linearly with coverage due to adsorbate/adsorbent interactions and it is given as follows equation (7):

$$
\mathrm{q}_{\mathrm{e}}=\mathrm{K}_{\mathrm{t}} \ln \mathrm{K}_{\mathrm{t}}+\mathrm{K}_{\mathrm{t}} \ln \mathrm{C}_{\mathrm{e}} \quad \text { Where } \quad \mathrm{B}_{\mathrm{t}}=\frac{\mathrm{RT}}{\mathrm{b}_{\mathrm{t}}}
$$

$\mathrm{K}_{\mathrm{t}}(\mathrm{L} / \mathrm{mg})$ is the constant of the Temkin isotherm, $\mathrm{b}_{\mathrm{t}}(\mathrm{J} / \mathrm{mol})$ is related to the heat of adsorption, $\mathrm{R}$ (8.314 $\left.\mathrm{J} / \mathrm{K}^{*} \mathrm{~mol}\right)$ is the gas constant and $\mathrm{T}(\mathrm{K})$ is the absolute temperature. The graph of Temkin isotherm is presented in (Fig. 2).

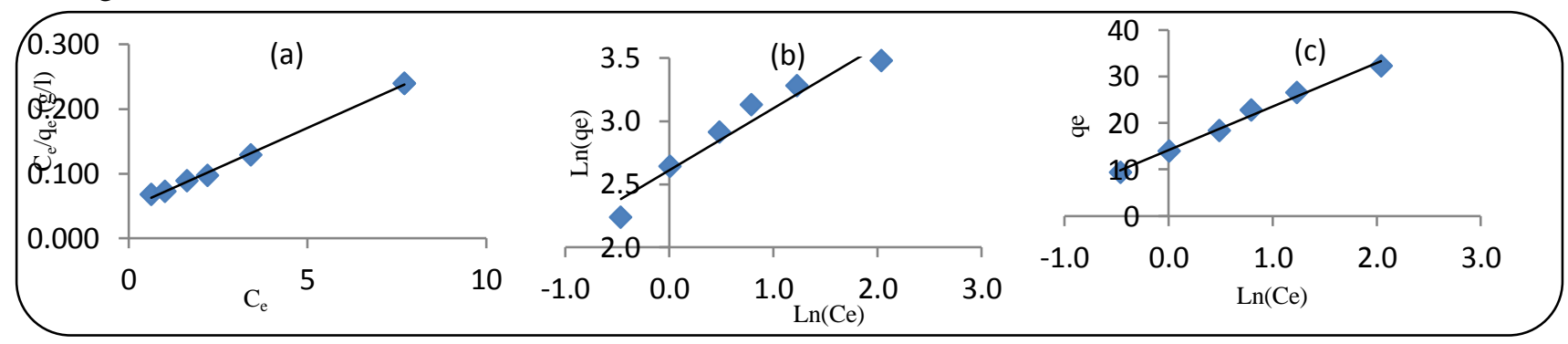

Fig. 2: Isotherms plots (a): Langmuir (b): Freundlich (c): Temkin

The constants of Langmuir ( $\mathrm{q}_{\mathrm{m}}$ and $\mathrm{b}$ ), Freundlich ( $\mathrm{K}_{\mathrm{F}}$ and $\mathrm{n}$ ) and Temkin $\left(\mathrm{k}_{\mathrm{t}}\right.$ and $\mathrm{b}_{\mathrm{t}}$ ) isotherm models with the corresponding correlation coefficients $\left(\mathrm{R}^{2}\right)$ are shown in TABLE 1 . The values of $\Delta \mathrm{q}_{\mathrm{e}}(\%)$ were also calculated and listed in TABLE 1

TABLE 1: Langmuir, Freundlich and Temkin isotherm Model Parameters for the Adsorption of MB onto Bagasse

\begin{tabular}{cllll}
\hline \hline \multirow{2}{*}{ Langmuir } & $\mathrm{q}_{\mathrm{m}}(\mathrm{mg} / \mathrm{g})$ & $\mathrm{b}(\mathrm{L} / \mathrm{mg})$ & $\mathrm{R}^{2}$ & $\Delta \mathrm{qe}_{\mathrm{e}}(\%)$ \\
& 41,667 & 0,511 & 0,998 & 1,917 \\
\hline \multirow{2}{*}{ Freundlich } & $\mathrm{K}_{\mathrm{F}}(\mathrm{mg} / \mathrm{g})(\mathrm{L} / \mathrm{mg}) 1 / \mathrm{n}$ & $\mathrm{n}$ & $\mathrm{R}^{2}$ & $\Delta \mathrm{q}_{\mathrm{e}}(\%)$ \\
& 13,599 & 2,041 & 0,936 & 5,231 \\
\hline \multirow{2}{*}{ Temkin } & $\mathrm{k}_{\mathrm{t}}(\mathrm{L} / \mathrm{mg})$ & $\mathrm{b}_{\mathrm{t}}(\mathrm{J} / \mathrm{mol})$ & $\mathrm{R}^{2}$ & $\Delta \mathrm{q}_{\mathrm{e}}(\%)$ \\
& 4,546 & 264,585 & 0,989 & 1,773 \\
\hline \hline
\end{tabular}

The $\Delta \mathrm{q}_{\mathrm{e}}$ values given in TABLE 1 ranged from 1.773 to 5.231, the Langmuir and the Temkin models presented the lower $\Delta \mathrm{q}_{\mathrm{e}}$. According to the obtained results, the Langmuir model describes better the adsorption process than the others models studied. This is also confirmed from the data of correlation coefficient $\left(\mathrm{R}^{2}\right)$. The correlation coefficient for the Langmuir and Temkin equation is high TABLE 1.

The maximum adsorption capacity obtained from the Langmuir equation was 41,667 $\mathrm{mg} / \mathrm{g}$ and the calculated values of $\mathrm{R}_{\mathrm{L}}$ for Langmuir model were in the range of $0.045-0,281$, they are between 0 and 1 this indicate that the adsorption is a favorable and useful process.

The value of $n>1$ in the Freundlich model, included in TABLE 1, suggest that MB is favorable physical process. This hypothesis is reinforced by the results of adsorption thermodynamics[12]. The constant $b_{t}$ is related to the heat of adsorption in Temkin model, and the positive value found $\left(b_{t}=264,585\right)$ indicates an exothermic process. 


\subsection{Adsorption Kinetics}

The adsorption kinetics is the second parameter indicating the reaction mechanisms of MB adsorption onto bagasse. In this study two kinetic models have been used: Lagergren pseudo-first order, Blanchard pseudosecond order, the best fit model was selected based on the linear regression correlation coefficient $\left(\mathrm{R}^{2}\right)$ and values of the normalized standard deviation $\Delta \mathrm{q}_{\mathrm{t}}(\%)$.

- Pseudo-first-order equation is given by equation (8):

$$
\ln \left(q_{e}-q_{t}\right)=\ln q_{e}-k_{1} t
$$

Where $\mathrm{q}_{\mathrm{e}}(\mathrm{mg} / \mathrm{g})$ and $\mathrm{q}_{\mathrm{t}}(\mathrm{mg} / \mathrm{g})$ are the amounts of $\mathrm{MB}$ adsorbed at equilibrium and at time $\mathrm{t}$ respectively, and $\mathrm{k}_{1}\left(\mathrm{~min}^{-1}\right)$ is the biosorption rate constant and can be obtained from the slope of plot $\ln \left(\mathrm{q}_{\mathrm{e}}-\mathrm{q}_{\mathrm{t}}\right)$ versus time $\mathrm{t}$ (not shown).

- Pseudo-second-order equation (9) is expressed by:

$$
\frac{\mathrm{t}}{\mathrm{q}_{\mathrm{t}}}=\frac{1}{\mathrm{k}_{2} \mathrm{q}_{\mathrm{e}}^{2}}+\frac{1}{\mathrm{q}_{\mathrm{e}}} \mathrm{t}
$$

Where $\mathrm{K}_{2}$ is the pseudo-second-order rate constant $\left(\mathrm{g} / \mathrm{mg}^{*} \mathrm{~min}\right)$. The slope of the plot between $\mathrm{t} / \mathrm{q}_{\mathrm{t}}$ versus $\mathrm{t}$ gives the value of $k_{2}$, and qe (Fig. 3)

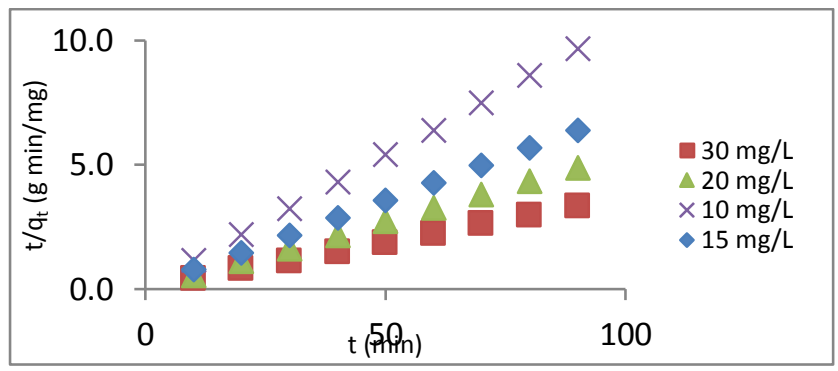

Fig. 3: Pseudo-second-order kinetic for the adsorption of MB dye on bagasse

The parameters of pseudo-first-order and pseudo-second-order kinetics models for the adsorption of MB on bagasse are presented in TABLE 2.

\begin{tabular}{|c|c|c|c|c|c|c|c|c|c|c|}
\hline \multirow[b]{2}{*}{$\begin{array}{l}\mathrm{C}_{\mathrm{i}} \\
(\mathrm{mg} / \mathrm{L})\end{array}$} & \multirow[b]{2}{*}{$\begin{array}{l}\mathrm{q}_{\mathrm{e}, \exp } \\
(\mathrm{mg} / \mathrm{g})\end{array}$} & \multicolumn{4}{|c|}{ Pseudo-premier ordre } & \multicolumn{5}{|c|}{ Pseudo-second ordre } \\
\hline & & $\begin{array}{l}\mathrm{q}_{\mathrm{e}, \mathrm{cal}} \\
(\mathrm{mg} / \mathrm{g})\end{array}$ & $\mathrm{k}_{1}(\min -1)$ & $\mathrm{R}^{2}$ & $\Delta \mathrm{q}_{\mathrm{t}}(\%)$ & $\begin{array}{l}\mathrm{q}_{\mathrm{e}, \mathrm{cal}} \\
(\mathrm{mg} / \mathrm{g})\end{array}$ & $\begin{array}{l}\mathrm{k}_{2} \\
(\mathrm{~g} / \mathrm{mg} * \min )\end{array}$ & $\mathrm{h}$ & $\mathrm{R}^{2}$ & $\Delta \mathrm{q}_{\mathrm{t}}(\%)$ \\
\hline 10 & 9,372 & 2,100 & 0,025 & 0,583 & 32,011 & 9,434 & 0,156 & 14,925 & 0,999 & 0,59 \\
\hline 15 & 13,993 & 4,175 & 0,085 & 0,865 & 30,274 & 14,286 & 0,064 & 13,158 & 1 & 0,319 \\
\hline 20 & 18,374 & 4,500 & 0,099 & 0,935 & 28,850 & 18,868 & 0,076 & 27,027 & 1 & 0,669 \\
\hline 30 & 26,584 & 3,920 & 0,042 & 0,826 & 33,083 & 27,778 & 0,019 & 14,925 & 0,999 & 0,592 \\
\hline
\end{tabular}

TABLE 2: Kinetic parameters of adsorption of MB onto bagasse at different initial dye concentrations

As can be seen in the table 3 the pseudo-second-order kinetic model has high values of the correlation coefficient, $\mathrm{R}^{2}$ closes to unity $(0,999-1)$ and has lower values of $\Delta \mathrm{q}_{\mathrm{t}}(0,319-0,669)$. It was found that this model yield better fittings for the adsorption of MB onto bagasse over the whole range of studied concentrations than the first-order kinetic model. Moreover, the calculated $\mathrm{q}_{\mathrm{e}}$ values $\left(\mathrm{q}_{\mathrm{e}, \mathrm{cal}}\right)$ obtained from the plots agreed very well with the experimental values $\left(\mathrm{q}_{\mathrm{e}, \mathrm{exp}}\right)$.

\section{Conclusion}

According to the obtained results, bagasse which was used without any pretreatment showed the applicability as an efficient adsorbent for cationic dye MB from aqueous solution. The kinetic studies showed better correlation coefficients and lowest $\Delta_{\mathrm{qt}}$ value for a pseudo-second-order kinetic model than pseudo-firstorder kinetic. Equilibrium data fitted very well with the Langmuir isotherm equation than the Temkin and Freundlich model and the dimensionless separation factor " $\mathrm{R}_{\mathrm{L}}$ " revealed the favorable nature of the isotherm of the adsorption process. 
The results obtained in this study indicate clearly that this waste and inexpensive biomaterial can be used as an adsorbent and a better alternative for the removal of MB dye from dye waste water treatment.

\section{References}

[1] B. H. Hameed, A. L. Ahmad, and K. N. A. Latiff, "Adsorption of basic dye (methylene blue) onto activated carbon prepared from rattan sawdust,” Dyes Pigments, vol. 75, no. 1, pp. 143-149, Jan. 2007.

https://doi.org/10.1016/j.dyepig.2006.05.039

[2] A. Ozer, G. Akkaya, and M. Turabik, "Biosorption of Acid Blue 290 (AB 290) and Acid Blue 324 (AB 324) dyes on Spirogyra rhizopus, ” J. Hazard. Mater., vol. 135, no. 1-3, pp. 355-364, Jul. 2006.

https://doi.org/10.1016/j.jhazmat.2005.11.080

[3] A. Ozer, G. Akkaya, and M. Turabik, "The removal of Acid Red 274 from wastewater: Combined biosorption and biocoagulation with Spirogyra rhizopus," Dyes Pigments, vol. 71, no. 2, pp. 83-89, 2006.

https://doi.org/10.1016/j.dyepig.2005.06.004

[4] N. Kannan and M. M. Sundaram, "Kinetics and mechanism of removal of methylene blue by adsorption on various carbons - a comparative study," Dyes Pigments, vol. 51, no. 1, pp. 25-40, 2001.

https://doi.org/10.1016/S0143-7208(01)00056-0

[5] Y. Xing, D. Liu, and L.-P. Zhang, "Enhanced adsorption of Methylene Blue by EDTAD-modified sugarcane bagasse and photocatalytic regeneration of the adsorbent," Desalination, vol. 259, no. 1-3, pp. 187-191, Sep. 2010.

https://doi.org/10.1016/j.desal.2010.04.008

[6] E. Khoramzadeh, B. Nasernejad, and R. Halladj, "Mercury biosorption from aqueous solutions by Sugarcane Bagasse," J. Taiwan Inst. Chem. Eng., vol. 44, no. 2, pp. 266-269, Mar. 2013.

https://doi.org/10.1016/j.jtice.2012.09.004

[7] M. Asgher and H. N. Bhatti, "Removal of reactive blue 19 and reactive blue 49 textile dyes by citrus waste biomass from aqueous solution: Equilibrium and kinetic study," Can. J. Chem. Eng., vol. 90, no. 2, pp. 412-419, Apr. 2012. https://doi.org/10.1002/cjce.20531

[8] N. Fayoud et al., "Kinetic, isotherm and thermodynamic studies of the adsorption of methylene blue dye onto agrobased cellulosic materials," Desalination Water Treat., vol. 57, no. 35, pp. 16611-16625, Jul. 2016.

https://doi.org/10.1080/19443994.2015.1079249

[9] D. Sud, G. Mahajan, and M. Kaur, "Agricultural waste material as potential adsorbent for sequestering heavy metal ions from aqueous solutions - A review," Bioresour. Technol., vol. 99, no. 14, pp. 6017-6027, Sep. 2008.

https://doi.org/10.1016/j.biortech.2007.11.064

[10] E.-K. Guechi and O. Hamdaoui, "Biosorption of methylene blue from aqueous solution by potato ( Solanum tuberosum ) peel: equilibrium modelling, kinetic, and thermodynamic studies," Desalination Water Treat., pp. 1-16, Apr. 2015.

[11] Y. Wang et al., "Application of a low-cost bagasse carbon-red mud (BCRM) adsorbent for adsorption of methylene blue cationic dye: adsorption performance, kinetics, isotherm, and thermodynamics, " Desalination Water Treat., pp. 1-11, Feb. 2015.

https://doi.org/10.1080/19443994.2015.1110538

[12] F. Moughaoui, M. Berrada, A. Bennamara, A. Abourriche, and Z. Anbaoui, "Adsorption study of methylene blue dye using Moroccan sugarcane bagasse," in Proc. Rencontres Scientifiques sur l'Environnement, 2016, pp. 109-115.

[13] A. M. M. Vargas, A. L. Cazetta, M. H. Kunita, T. L. Silva, and V. C. Almeida, "Adsorption of methylene blue on activated carbon produced from flamboyant pods (Delonix regia): Study of adsorption isotherms and kinetic models," Chem. Eng. J., vol. 168, no. 2, pp. 722-730, Apr. 2011. 
https://doi.org/10.1016/j.cej.2011.01.067

[14] C. H. Giles, T. H. MacEwan, S. N. Nakhwa, and D. Smith, "786. Studies in adsorption. Part XI. A system of classification of solution adsorption isotherms, and its use in diagnosis of adsorption mechanisms and in measurement of specific surface areas of solids, ”J. Chem. Soc. Resumed, p. 3973, 1960. 